\title{
Tibiofemoral contact properties for different flexion angles on injured ACL knee joint
}

\section{Propiedades de contacto tibiofemoral para diferentes ángulos de flexión en rodilla por lesión de LCA}

\author{
Daniel F. Chaparro ${ }^{1}$, Cesar A. Herrera ${ }^{2}$, Diego F. Villegas ${ }^{3}$ \\ ${ }^{1}$ Universidad Industrial de Santander, Escuela de Ingeniería Mecánica, Bucaramanga, Colombia. \\ Email: daniel2188201@ correo.uis.edu.co \\ ${ }^{2}$ Instituto Tecnológico y de Estudios Superiores de Monterrey, Departamento de Mecatrónica, Toluca, México. \\ Email: a01368741@itesm.mx \\ ${ }^{3}$ Universidad Industrial de Santander, Escuela de Ingeniería Mecánica, Bucaramanga, Colombia. Email: dfvilleg@uis.edu.co
}

Received: March 10, 2018. Accepted: May 11, 2018.Final version: June 2, 2018.

\begin{abstract}
At normal conditions, one of the most important knee stabilizers is the Anterior Cruciate Ligament (ACL). Seven pig knees were subjected to a $700 \mathrm{~N}$ compressive load at three different flexion angles $\left(70^{\circ}, 55^{\circ}\right.$ and $\left.40^{\circ}\right)$ using a universal testing machine MTS Bionix 515.11. Contact pressure, contact area and peak force were obtained for healthy knees and ACL hyper-extension injury was induced to the knee by a load in the posterior side of the tibia with the knee at full extension until the ligament failed. The obtained results showed statistically significant differences $(\mathrm{p}<0.05)$ for the contact pressure for the highest angle evaluated vs all the other angles in an injured knee. To the contact area with some little differences. Lastly, for the peak force statistically significant differences were found in almost all the conditions denoting the importance of the ACL as a primary stabilizer. The present study sought to determine the contact mechanics on healthy and ACL ruptured knees.
\end{abstract}

Keywords: ACL; tibiofemoral contact properties; knee joint; osteoarthritis; pressure sensor.

\section{Resumen}

En condiciones normales, uno de los estabilizadores de rodilla más importante es el Ligamento Cruzado Anterior (LCA). Siete rodillas de cerdo fueron sometidas a una carga de compresión de $700 \mathrm{~N}$, a tres diferentes ángulos de flexión $\left(70^{\circ}, 55^{\circ}\right.$ y $\left.40^{\circ}\right)$, usando una máquina universal de ensayos MTS Bionix 515.11. Se obtuvieron presiones de contacto, área de contacto y fuerza pico para rodillas sanas y rodillas con LCA lesionado por hiperextensión inducido por una carga a la rodilla, en la parte posterior de la tibia, con la rodilla en extensión completa hasta que el ligamento falló. Los resultados obtenidos mostraron diferencias significativas $(\mathrm{p}<0.05)$ para la presión de contacto para el más grande ángulo evaluado vs. todos los otros ángulos en la rodilla lesionada. Para el área de contacto hubo solo algunas pequeñas diferencias. Por último, la fuerza pico tuvo diferencias estadísticamente significativas en casi todas las condiciones, lo que denota la importancia del LCA como estabilizador primario. Este estudio busca determinar la mecánica del contacto tibiofemoral en rodillas sanas y con ruptura de LCA.

Palabras clave: LCA; propiedades de contacto tibio-femoral; rodilla; osteoartritis; sensor de presión.

ISSN impreso: 1657 - 4583, ISSN en línea: 2145 - 8456

Este artículo puede compartirse bajo la licencia CC BY-ND 4.0 y se referencia usando el siguiente formato: D. Chaparro, C. Herrera, D. Villegas "Tibiofemoral contact properties for different flexion angles on injured ACL knee joint," Rev. UIS Ing., vol. 17, no. 2, pp. 283-290, 2018. Doi: https://doi.org/10.18273/revuin.v17n2-2018024 


\section{Introduction}

Human locomotion is possible because of the musculoskeletal system. Bones, muscles, tendons and ligaments work together to cause movement of limbs by means of the joints. The knee is the largest synovial joint. A hinge joint which allows flexion-extension and rotation of lower limbs. Knee is composed by: two main bones, tibia and femur, articular cartilage, lateral and medial menisci, and four main ligaments, two collaterals, LCL (Lateral Collateral Ligament) and MCL (Medial Collateral Ligament), and two cruciate: PCL (Posterior Cruciate Ligament) and ACL.

Anterior Cruciate Ligament (ACL) has been widely studied because is the most commonly injured knee ligament [10]. At least one of 3,000 people suffer an ACL rupture. Therefore, about 100,000 reconstructive ACL interventions are made per year [20].

The ACL is composed by two bundles: the anteromedial and the posterolateral. It has a primary role in extension and secondary in the genu varum prevention. Also, it inhibits the abnormal external rotation of the knee [26].

The ACL rupture, or even tears, leads to a detriment of the tissue surrounding like articular cartilage and menisci, mainly the lateral menisci $[6 ; 29]$. At the same time, the menisci cover about the $70 \%$ of the total contact area in the knee joint, and the pressure can rise up to twofold respect to a healthy knee [36]. Moreover, ACL rupture is one of the main causes for Osteoarthritis (OA) progression because it increases the rate of loss cartilage, especially in the medial compartment [37]. Likewise, a half of the patients with ACL rupture and menisci tears will get OA after within 10 to 20 years, with the associated pain and functional impairment [25].

Pressure film sensors have been widely used to measure contact properties in joints. Tekscan system has several advantages over others like the Fuji film [24]. Previous studies have reported tibiofemoral contact properties for different animals, including porcine [22] and also for human knee [34, 39]. Most of the studies done on tibiofemoral contact mechanics make the comparison between and intact knee and injured menisci and their roots $[23,34,35]$. However, a few works have studied the tibiofemoral contact mechanics following an ACL rupture. This study seeks to determine how the contact mechanics changes when a ACL rupture is artificially induced by hyperextension and even more how it changes on flexed knee.

\section{Methodology}

\subsection{Specimen Preparation}

Seven pig knee joints, with an age of 4 months average, were obtained from a slaughterhouse. The dissection process was made taking care on preserving all soft tissue surrounding the articular capsule. About $15-\mathrm{cm}$ above and below the knee join were harvested. Then, the proximal femur and distal tibia were potted with resin in a 5-cm PVC pipe to facilitate on fixing the specimen to the 6-DOF device which allowed to obtain the knee flexion angles (see Figure 1). The femur attaches to a cylinder which has a ball joint allowing rotations on the three planes, and the tibia potted goes into a cylinder which distal end allow rotations on the sagittal and transversal planes. The specimens were wrapped in saline soaked gauze and frozen at $-18{ }^{\circ} \mathrm{C}$. On the day of testing, the samples were thawed at room temperature $\left(26{ }^{\circ} \mathrm{C}\right.$ on average) for 4 hours. The knees were sprayed each 15 minute with a saline water solution to preserve the joint moisture during the test. Healthy knees were tested, and contact properties obtained. Subsequently, ACL of each knee was subjected to rupture by hyperextension. A small device was built to keep the femur fixed while a load was applied on the posterior side of the tibia until the ligament failed by excessive anterior tibial translation. This is a type of injury which is common in athletes who practice high contact sports like football or soccer [30]. After the test, all knees tested were explored inside to determine if menisci or other tissue tear as well.

\subsection{Test setup}

A universal testing machine (MTS Bionix 307.02, MTS System Corporation, Minneapolis, MN, USA), was used to perform the test. The 6-DOF compressive device was attached to the machine attaching the proximal femur and distal tibia on it (see Figure 1). Before each test, femoral cylinder was allowed to rotate freely moving down the MTS actuator in order to have eliminate either varus or valgus rotations. Subsequently, three angles $\theta$ of flexion were set up to 70,55 and 40 degrees moving the part (D) of the device (Figure 1). Once the flexion angle was verified with a protractor, the upper fixture (A) was fixed, and a compressive load of 700-N (1BW) was applied to the knee. A Tekscan flexible sensor (K-scan Model 4000, 9000psi; Tekscan Inc., South Boston, MA) was used to record contact pressure, contact area, and peak force. The sensor was previously calibrated by applying 3 different compressive loads using a flat-ended plate attached to the MTS actuator. 


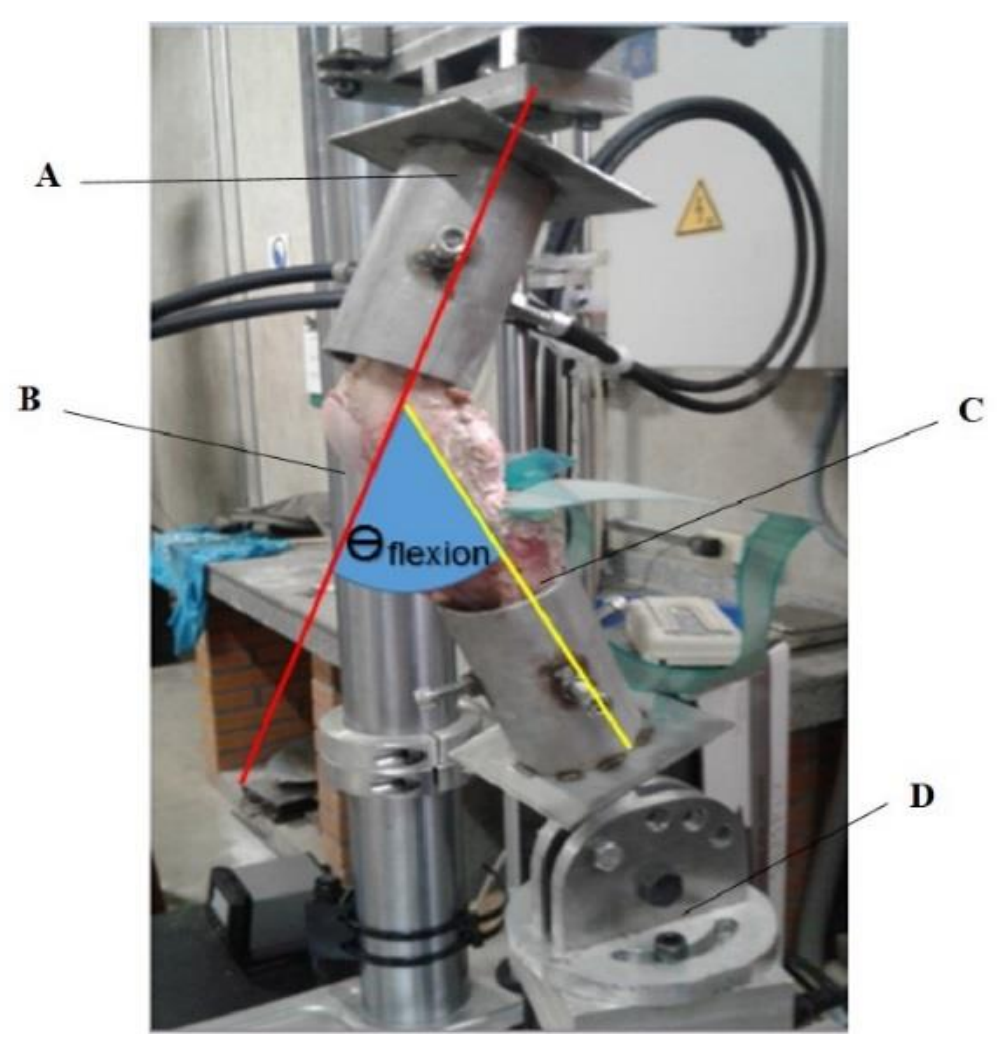

Figure 1. Experimental setup. (A) Ball bearing, (B) Knee joint, (C) K-4000 Tekscan sensor, (D) Tibia holding device with adjustable flexion angle.

\subsection{Statistical Analyses}

Grubb's test was used to reject outliers or erroneous data for each of the three of contact properties considered. Average and standard deviation were calculated to report data. One-way analysis of variance (ANOVA) was performed to make comparisons of the contact pressure, peak force and contact area with healthy knee and ACL injured knee for the three angles. Significant differences were identified using a significance level of $5 \%(\mathrm{p}<0.05)$.

\section{Results}

Contact properties were measured for Healthy (HK) and Injured Knees (IK). Significant differences were found between a HK-70 and IK-three angles for Contact Pressure (CP). Interesting results are shown in Figure 2, there are a decreasing in $12 \%$ in $\mathrm{CP}$ from $\mathrm{HK}$ to IK at $70^{\circ}$, an increasing of $33 \%$ at $55^{\circ}$, and only an increasing of $5 \%$ was observed at $40^{\circ}$. The patterns of the sensors (Figure 3) showed a similar tendency to that shown in Figure 2. After the ACL induced injury, a decreasing for largest flexion angle $\left(70^{\circ}\right)$ and an increasing for the remaining two angles $\left(55^{\circ}\right.$ and $\left.40^{\circ}\right)$. Moreover, healthy knees increase their $\mathrm{CP}$ as flexion angle increases as well.
PF (Peak force) in HK are higher than IK at the three angles tested in a range of $18 \%$ to $32 \%$. Peak force diminishes as flexion angle decreases in both healthy and injured knees. However, it seems there is no change for $\mathrm{PF}$ in $\mathrm{HK}$ at 55 and 40. ANOVA showed that in most of the cases a significant difference was found when a HK is compared with a IK $(\mathrm{p}<0.05)$.

Once the mechanical test was done, a morphological analysis was made to explore the knee inside and report the damage that no only ACL had but other soft tissue surrounding elicited after an excessive anterior translation for the tibia. All the knees had an ACL ruptured. It was seen little depressions on the medial and lateral femoral condyles with more intensity on the lateral looking color purple in several zones which could be due to the compression loads on the knee without ACL. Some of the knees showed partial rupture of the anterior meniscal attachment. Similarly, injury on the lateral tibial condyle was characterized by a contusion area. Depressions on the tibial plateau, both medial and lateral condyles, by axial flattening with purple coloration as a result of the axial compressive forces. 


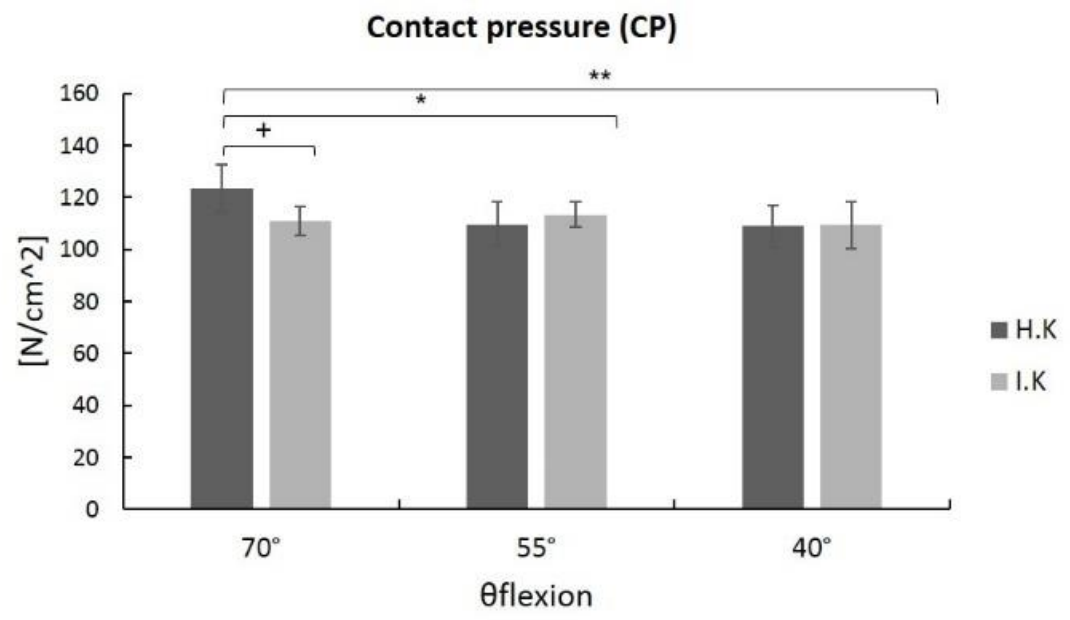

Figure 2. Contact pressure. Average and standard deviation. ${ }^{+}$Significant differences found between $\mathrm{HK}$ and $\mathrm{IK}$ at $70^{\circ}$ ( $\mathrm{p}<0.05$ ). * significant differences between HK-70 and IK-55 ( $\mathrm{p}<0.05)$, ** significant differences between HK-70 and IK-40 $(\mathrm{p}<0.05)$

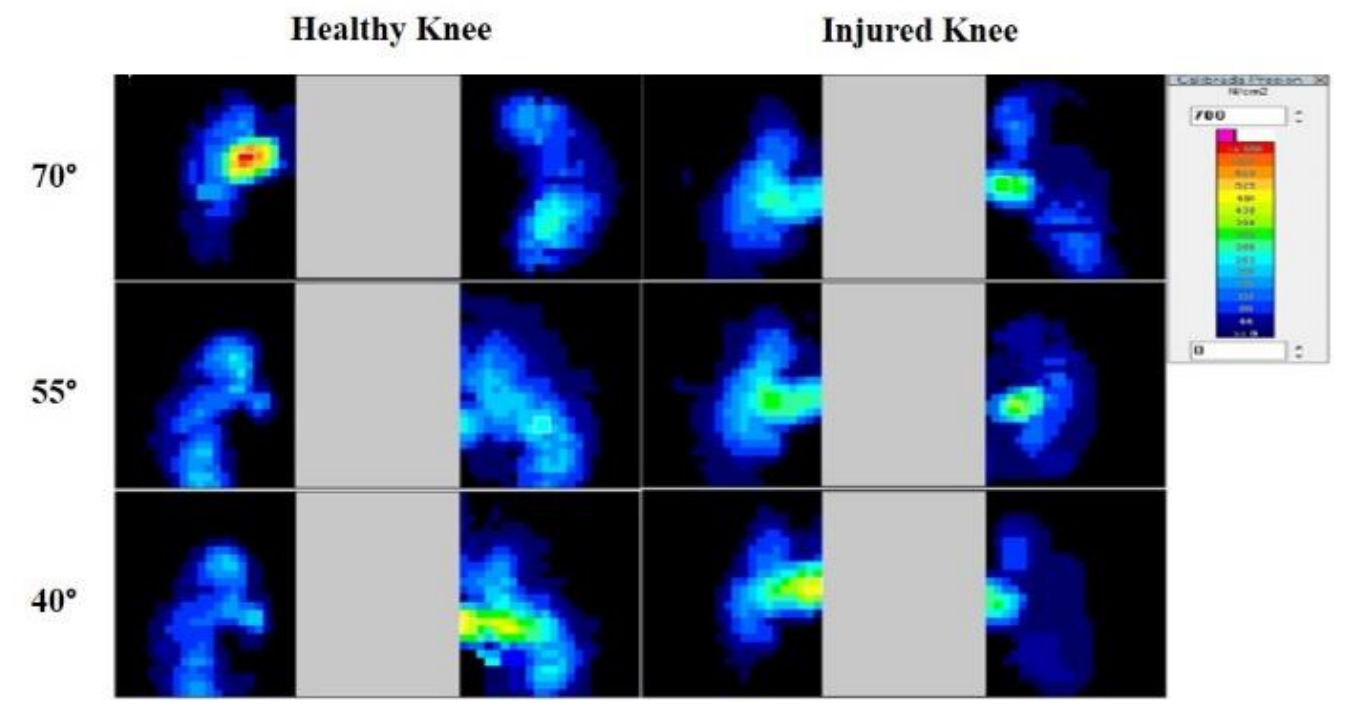

Figure 3. Contact pressure at the tibial plateau for a representative knee.

On the other hand, significant differences were found on $\mathrm{HK}$ and $\mathrm{IK}$ at $70^{\circ}$, and $\mathrm{IK}-70^{\circ}$ and $\mathrm{HK}-55^{\circ}$. CA (Contact Area) on healthy knees increased $10 \%$ from $70^{\circ}$ to $55^{\circ}$ and then decreased $18 \%$ from $55^{\circ}$ to $40^{\circ}$. On the contrary, IK slightly increases as angle decreases. In addition, no significant differences were found between $\mathrm{HK}$ and IK for $55^{\circ}$ and $40^{\circ}$ flexion angles.

\section{Analysis of results}

The present study sought to determine the contact mechanics on healthy and ACL ruptured knees. Contact properties were measured using a pressure sensor at three different angles. The results obtained agree with previous studies which reported similar Peak Forces [9]. The implementation of new alternatives for the study of the human knee without using actual human knees is one of the focus of study in the present days, so in order to achieve that goal there are many studies in the specialized literature that have tried to find a suitable animal specimen whose knees are very similar to the human and some studies showed that the more appropriate animal is the pig in the anatomical aspect $[3,28]$. In addition, from this point of view, other studies exposed that animal 
gender is not a factor that should be considered because the measurements for both are very similar [1]. In the biomechanical aspect, the similarity between human and pig knees were also studied and the results showed no significant statistically differences for in situ forces in the ACL and the direction of them [21].

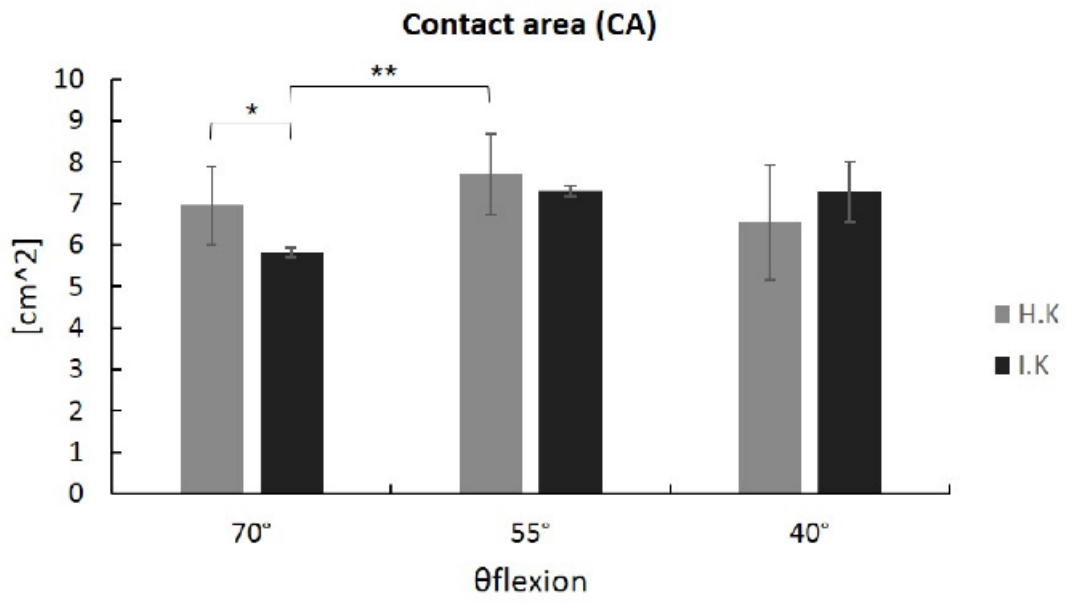

Figure 1. Contact area. Average with standard deviation and significant differences between $\mathrm{HK}$ and IK at $70^{\circ}(\mathrm{p}<0.05)$ and IK70 with HK-55 (p<0.05).

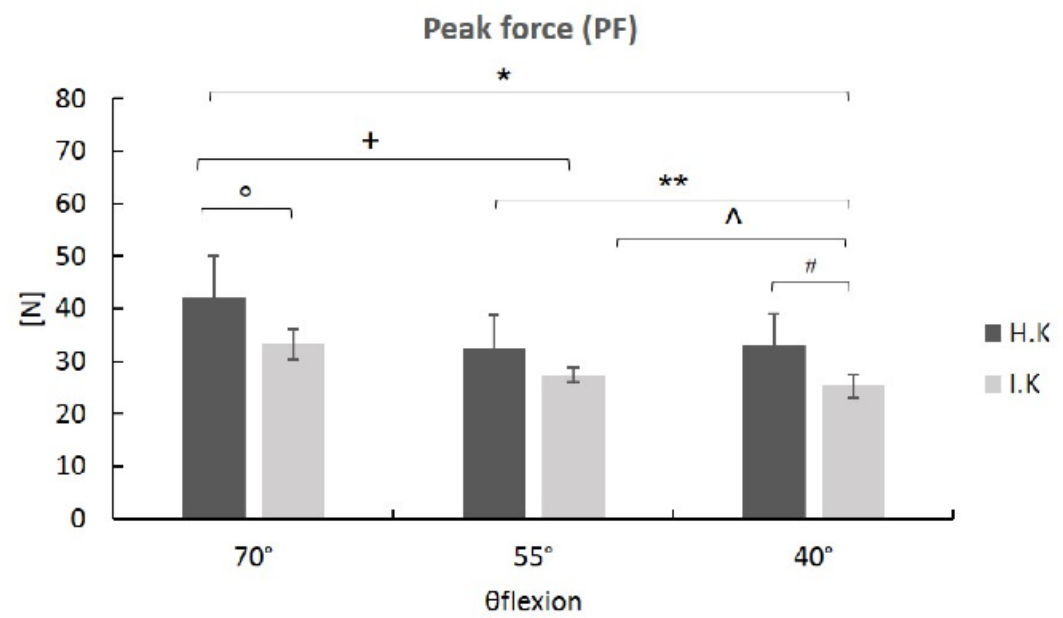

Figure 5. Data is shown in mean + standard deviation. * Significant differences between HK-70 and IK-40, ${ }^{+}$significant differences between HK-70 and IK-55, ${ }^{\circ}$ significant differences between HK and IK at 70, ** significant differences between HK-55 and IK$40, \wedge$ significant differences between IK-55 and HK-40, and \# significant differences between HK and IK at 40 (p < 0.05$)$

The results obtained in this study show a highly incidence of the ACL rupture in the knee biomechanics. Perhaps, contact pressure is the more measured parameter in contact mechanics. It was seen that $\mathrm{CP}$ of an IK at 70 was lower than the $\mathrm{HK}$, which was different that it was expected. However, CP at other two angles (55 and 40) remains the same. Similarly, CA and PF decreases at 70 of flexion. It is possible that load had been taken for other structures like the menisci. A previous study showed that tibiofemoral contact pressure increases as flexion angle increases because of a meniscectomy [31]. It is important to notice that contact pressure remains almost constant at 55 and 40 for both healthy and injured knee. It suggests that for low flexion angles the ACL has not a strong 
influence on the tibiofemoral contact mechanics. On the contrary, a previous study suggests that ACL primary functions diminishes as flexion angle increases [15]. It is known that ACL plays an important role as knee stabilizer [10]; hence, its behavior on dynamic loads maybe different.

Regarding to the contact area and peak force, it is seen a slightly decrease as flexion angle increases in injured knees for CA unlike the PF which increase as flexion increases. These results agree with values obtained for contact pressures in this study because it remains almost constant regardless the flexion angle. On the other hand, peak force was the parameter having more significant differences between flexion angles, and healthy and injured knees, perhaps because of the primary role stabilizer that ACL fulfills and because of its rupture, the loads cannot be properly distributed which is the primary reason of the subsequent wounds that affect the knee [6, 17, 25, 29]. Although, PF values did not change drastically, they vary proportionally to the flexion angle. It is possible that as flexion angle increases femoral condyle moves on the posterior side of the knee loading the menisci and their posterior horns. Consequently, as ACL tears, other structures must take its role. Therefore, it is probably that menisci and horns increased their contact area and the tibia plateau elicit higher load.

On the other hand, it is common that ACL induced rupture, due to abnormal anterior tibial translations, cause collateral damages over soft tissue in the knee joint. Tear of lateral meniscus occurs almost immediately after the ACL rupture [29] and it was corroborated by the morphological analysis of the porcine knees used in this study. This study was made on porcine knees because of the difficulty on obtaining human knees. However, previous studies have shown biomechanics in porcine knees can be extrapolated to human knee behavior [21]. It is well known the knee stabilizer role of ACL [10]. Therefore, it was challenging to keep knees stable during the test, a non-contact injury that consist in a rotational force on the shinbone keeping the femur static is often used to induce ACL rupture [7]. Also, this study did not considerate the laterality on the specimen; hence, the differences between right and left joint were not assessed although is known that on limb dominance has an important role on normal activities as walk, climbing stairs and run [12], for that reason in future studies the consideration of the limb predominance and how it affects the IP, CA and PF is suggested.

In summary, it was found that contact pressure did not change significantly at three flexion angle $\left(70^{\circ}, 55^{\circ}\right.$ and $40^{\circ}$ ). However, contact area decreases and peak force increase as flexion angle increases. The results obtained in this study are relevant because they suggest that ACL has not a strong impact on the tibiofemoral contact mechanics, although, the knee biomechanics change indeed because other structures on the knee will support more loading. This work will help to orthopedic surgeons taking decision on what patients really need an ACL replacement, notwithstanding the surgical intervention cannot guarantee a fully recover and even if the procedure is successful with the years the development of osteoarthritis can be a possibility [2, 13, 16]. Next step for understanding the tibiofemoral contact mechanics must involve deep flexion angles and, assess differences between medial and lateral compartments of the knees.

\section{Aknowledgements}

The authors would like to thank Ivan Quintero, MD because of his valuable contribution on this work.

\section{References}

[1]. A.M. Kiapour, M.R. Shalvoy et al., "Validation of Porcine Knee as a Sex-specific Model to Study Human Anterior Cruciate Ligament Disorders", Clinical Orthopaedics and Related Research, vol. 473, no.2, pp. $639-650,2014$

[2]. B.E. Øiestad et al., "Knee function and prevalence of knee osteoarthritis after anterior cruciate ligament reconstruction: A prospective study with 10 to 15 years of follow-up", American Journal of Sports Medicine, vol. 38, no. 11, pp. 2201-2210, 2010.

[3]. B.L. Proffen et al., "A comparative anatomical study of the human knee and six animal species", Knee, vol. 19, no. 4, pp. 493-499, 2012.

[4]. D. F. Villegas et al. "A quantitative study of the microstructure and biochemistry of the medial meniscal horn attachments", Annals of biomedical engineering, vol. 36, no 1, p. 123-131, 2008

[5]. D. F. Villegas et al. "Failure properties and strain distribution analysis of meniscal attachments", Journal of biomechanics, vol. 40, no 12, p. 2655-2662, 2007

[6]. D.K. Nikolić. "Lateral meniscal tears and their evolution in acute injuries of the anterior cruciate ligament of the knee. Arthroscopic analysis", Knee surgery, sports traumatology, arthroscopy: official journal of the ESSKA. 1998, vol. 6, pp. 26-30, pp. 2630, Jan. 1989.

[7]. E.G. Meyer and R.C. Haut, "Anterior cruciate ligament injury induced by internal tibial torsion or 
tibiofemoral compression", Journal of Biomechanics, vol. 41, no. 16, pp. 3377-3383, 2008

[8]. E.G. Meyer and R.C. Haut, "Excessive compression of the human tibio-femoral joint causes ACL rupture", Journal of Biomechanics, vol. 38, no. 16, pp. 2311-2316, 2005.

[9]. E.J. Miller et al., "Experimental validation of a tibiofemoral model for analyzing joint force distribution", Journal of Biomechanics, vol. 42, no. 9, pp. 1355-1359, 2009

[10]. F. Forriol, A. Maestro y J. Vaquero. "El ligamento cruzado anterior: morfología y función." Trauma Fund MAPFRE 19, pp $^{\circ}$ 7-18, 2008

[11]. F. Garcia Perez, M. Florez-Garcia. "Escalas de valoración funcional en lesiones ligamentosas de rodilla", Revista de la Sociedad Española de Rehabilitación y Medicina Física: Vol. 28, p. 456-464, junio, 1994.

[12]. F.P. Carpes et al., "On the bilateral asymmetry during running and cycling - A review considering leg preference", Physical Therapy in Sport, vol. 11, no. 4, pp. 136-142, 2010

[13]. Ferretti et al., "Osteoarthritis of the knee after ACL reconstruction", International Orthopaedics, vol. 15, no. 4, pp. 367-371, 1991

[14]. Georgoulis et al., "Tibial rotation is not restored after ACL reconstruction with a hamstring graft", Clinical Orthopaedics and Related Research, no. 454, pp. 89-94, 2007

[15]. Guoan Li, et al, "In vivo kinematics of the ACL during weight-bearing knee flexion", Journal of orthopaedic research, vol. 23, no 2, p. 340-344, 2005

[16]. H. Jonsson et al., "Positive pivot shift after ACL reconstruction predicts later osteoarthrosis: 63 Patients followed 5-9 years after surgery", Acta Orthopaedica Scandinavica, vol. 75, no. 5, pp. 594-599, 2004

[17]. J. Gillquist and K. Messner, "Anterior cruciate ligament reconstruction and the long-term incidence of gonarthrosis", Sports medicine (Auckland, N.Z.), vol. 27, no. 3, pp. 143-156, 1999

[18]. J. Guillen, J. Jiménez. “Anatomía Quirúrgica de la Rodilla”, Revista Ortopédica de Trauma. vol. 28, fascículo 3, 1984
[19]. J. Robinson et al. "Two-bundle, four-tunnel anterior cruciate ligament reconstruction", Knee Surgery, Sports Traumatology, Arthroscopy, vol. 14, p. 629-636, Julio, 2006

[20]. J.D. Ayala-mejías, G.A. García-Estrada and L. Alcocer Pérez-España, "Lesiones del ligamento cruzado anterior”, vol. 28, no. 1, pp. 57-67, 2014

[21]. J.W. Xerogeanes et al., "A functional comparison of animal anterior cruciate ligament models to the human anterior cruciate ligament", Annals of biomedical engineering, vol. 26, no. 3, pp. 345-52, 1998

[22]. Jeong-Hee Seo, et al. "Effect of repair of radial tears at the root of the posterior horn of the medial meniscus with the pullout suture technique: a biomechanical study using porcine knees", Arthroscopy, vol. 25, no 11, p. 1281-1287, 2009

[23]. Jin Goo Kim, et al, "Tibiofemoral contact mechanics following posterior root of medial meniscus tear, repair, meniscectomy, and allograft transplantation", Knee Surgery, Sports Traumatology, Arthroscopy, vol. 21, no 9, p. 2121-2125, 2013

[24]. Kent N. Bachus, et al. "Measuring contact area, force, and pressure for bioengineering applications: using Fuji Film and TekScan systems", Medical engineering and physics, vol. 28, no 5, p. 483-488, 2006

[25]. L.S. Lohmander, P.M. Englund et al., "The longterm consequence of anterior cruciate ligament and meniscus injuries: Osteoarthritis", American Journal of Sports Medicine, vol. 35, no. 10, pp. 1756-1769, 2010

[26]. M. A. Campuzano-Marín. "Predicción diagnóstica en las lesiones del ligamento cruzado anterior. Madrid". Universidad Complutense de Madrid. Facultad de Medicina. Departamento de Cirugía, 1998. 188 p.

[27]. M. C. Panesso et al. "Biomecánica clínica de la rodilla". Facultad de Rehabilitación y Desarrollo Humano. Bogotá D.C.: Editorial Universidad del Rosario, 2009. 40 p. - (Documento de investigación; 39).

[28]. M.F. Arruda and G. Salomão, "Morphological Characterization and Preparation of Knee Joint Porcino, Verisimilitude and Contributions as Alternative Material for Teaching Human Anatomy", vol. 3, no. 7, pp. 35-41, 2015

[29]. M.L. Killian, D.I. Isaac et al., "Traumatic anterior cruciate ligament tear and its implications on meniscal degradation: A preliminary novel lapine osteoarthritis 
model" Journal of Surgical Research, vol. 164, no. 2, pp. 234-241, 2010

[30]. N. Wetters et al., "Mechanism of Injury and Risk Factors for Anterior Cruciate Ligament Injury", Operative Techniques in Sports Medicine, vol. 24, no. 1, pp. 2-6, 2016

[31]. Nikhil N. Verma, et al, "The effects of medial meniscal transplantation techniques on intra-articular contact pressures", J Knee Surg, vol. 21, p. 20-26, 2008

[32]. R. Linares B. "Diseño y construcción de un banco experimental adaptable a una máquina universal de ensayos MTS 810 para el análisis biomecánico de la articulación de la rodilla del cuerpo humano bajo la acción de diferentes tipos de carga estática". Trabajo de grado Ingeniero Mecánico. Bucaramanga.: Universidad Industrial de Santander. Facultad de Ingenierías FísicoMecánicas. Escuela de Ingeniería Mecánica, 2015. 98 p.

[33]. S. T Hanley, R. F. Warren. "Arthroscopic meniscectomy in the anterior cruciate ligament-deficient knee", Arthroscopy, vol 3, p. 59-65,1987

[34]. Sally Arno, et al, "Tibiofemoral contact mechanics following a horizontal cleavage lesion in the posterior horn of the medial meniscus", Journal of Orthopaedic Research, vol. 33, no 4, p. 584-590, 2015

[35]. Stephen J. Lee, et al, "Tibiofemoral contact mechanics after serial medial meniscectomies in the human cadaveric knee", The American journal of sports medicine, vol. 34, no 8, p. 1334-1344, 2006

[36]. T. Fukubayashi, H. Kurosawa, "The contact area and pressure distribution pattern of the knee: A study of normal and osteoarthrotic knee joints", Acta Orthopaedica, vol. 51, no. 1-6, pp. 871-879, 1980

[37]. T.P. Andriacchi et al., "Changes at the knee after ACL injury cause cartilage thinning", Clinical Orthopaedics and Related Research, no. 442, pp. 39-44, 2006

[38]. V. Valencia-Aguirre, C. Mejía-Echeverría, V. Erazo-Arteaga, "Desarrollo de una prótesis de rodilla para amputaciones transfemorales usando herramientas computacionales. CAD-CAE-CAM," Rev. UIS Ing., vol. 16, no. 2, pp. 23-34, 2017. DOI: https://doi.org/10.18273/revuin.v16n2-2017002
[39]. V.C Mow and W.C Hayes, en Basic Orthopaedic Biomechanics, $2^{\text {nd }}$ ed. Lippincott-Raven, 1997. ISBN 0397516843.

[40]. Y. Morimoto et al., "Tibiofemoral Joint Contact Area and Pressure After Single- and Double-Bundle Anterior Cruciate Ligament Reconstruction", Arthroscopy - Journal of Arthroscopic and Related Surgery, vol. 25, no. 1, pp. 62-69, 2009 